\title{
MIRANDA, Julia.
}

Frenética armonía.

Vanguardias poéticas

Latinoamericanas en la

Guerra Civil Española.

Rosario: Beatriz Viterbo, 2016, 368 p.

Ivan Martucci Forneron

Recebido em: 10 de fevereiro de 2017

Aceito em: 23 de abril de 2017

Ivan Martucci Forneron

Doutor em Letras pelo Programa

de Pós-Graduação em Língua

Espanhola e Literaturas Espanhola

e Hispano-Americana da

Universidade de São Paulo

(USP). Atualmente é professor

substituto na mesma universidade,

responsável pela disciplina

de Literatura Espanhola do

Século XX.

Contato: imafor@usp.br 
O projeto de poder político e cultural espanhol levado a cabo durante a ditadura franquista (1939-1975) foi tão eficaz no seu intuito de eliminar o que lhe era divergente por meio de uma propaganda histórica reversa e seus contundentes apagamentos de memórias individuais e coletivas que todo estudo que dialogue com a Guerra Civil Espanhola (1936-1939) parece exigir um cuidadoso exercício arqueológico de revelaçóes que reescrevem a Espanha como se a reinterpretássemos tal qual um mito: incansavelmente e com interesse renovado. Não é por outra razão que os muitos estudos sobre esse período de desastres da década de 1930, apesar de contar com investigaçóes e trabalhos abrangentes nos mais diversos campos, sejam eles com enfoques historiográficos, políticos, econômicos ou literários, ainda são insuficientes para o entendimento do século XX espanhol, por conta das grandes lacunas e (in)explicáveis ausências acumuladas sob os destroços de um tempo cujo processo de resgate à guisa de reparação obriga-nos a um olhar amplo e, por vezes, multidisciplinar para concatenar um estudo que parte de uma miríade de fios rotos e desencapados. As grandes lacunas a que nos referimos anteriormente, portanto, constituem as palavras-chave de uma história de retalhos que as versóes oficiais relegaram a extensas notas de rodapé. Isso porque, e, aqui, em nosso caso, no campo da literatura, visitar essas lacunas nos remete ao assunto mais espinhoso da historiografia literária espanhola, a escrita desse tempo e o seu rosto e testemunho que se tentou borrar dos mapas mentais, algo que podemos dispor nessa ordem: 1) o evento da II República em 1931; 2) os ousados projetos de transformaçáo política, econômica e cultural republicanos e, por conta disso, uma forte 
resistência conservadora que cria uma instabilidade social constante; 3) crescentes diferenças acirradas no tecido social e nas instituiçóes; 4) a tentativa militar fracassada de um de golpe de estado; 5) a organização armada de grupos antagônicos; 6) a nova sublevação militar com o apoio da Igreja e dos latifundiários; 7) o início da Guerra Civil; 8) a derrota da República e a perseguição a seus apoiadores; 9) o exílio e os exilados; 10) a Espanha da península com seu silenciamento, prisóes, torturas e exílio interior, e a Espanha peregrina com seus exilados dispersos pelo mundo; e 11) uma ditadura que resolveu escrever a história da nação espanhola como uma farsa anacrônica e violenta, mediada pelo terror e o silêncio.

Percurso básico de interrogaçóes iniciais de quem deseja ler a Espanha moderna, essa sequência trágica, pensemos, mais o decurso de quase 40 anos do regime franquista, quantas fissuras e pontos irreconciliáveis não produziu nos alicerces da nação espanhola? Pois bem, se para os espanhóis essa experiência-herança, com mais de 80 anos, além de aberta, e da lenta reparação e reconhecimento é tão inconveniente e entorpecedora aos seus ânimos, sem falar na quantidade crescente de espanhóis que ignora ou nem mesmo reconhece a gravidade do evento histórico/político/cultural da Guerra Civil e suas consequências, o que pode ser dito dos trabalhos investigativos que, além de enfrentarem a anteriormente citada sequência trágica, ainda extrapolam seu território e ampliam nosso olhar para o universo estético-político ou ético-estético, ao transporem essa narrativa para o campo das poéticas latino-americanas e sua atuação durante a Guerra Civil Espanhola? Pois é disso que trata a admirável obra intitulada 
Frenética armonía. Vanguardias poéticas latinoamericanas en la Guerra Civil Española, da autora Julia Miranda, obra que, além de necessária, é rara, pois sua investigação abrangente nos proporciona novas chaves para interrogarmos - ou reinterpretarmos - o "mito" Espanha.

Ler a Guerra Civil Espanhola como uma miniatura do século XX é uma citação muito precisa do filósofo Alain Badiou que a autora traz para expor a amplitude e a reverberaçáo do conflito. O estudo de Julia Miranda nos faz ver com clareza como a intervençáo dos poetas, nesse caso, dos latino-americanos, contribuiu para a internacionalização da Guerra Civil Espanhola e, ao aumentar seu alcance, mesmo ficcionalizado na escritura dessa poesia, expôs a gravidade do conflito, alçando-o como um tema, um mote próprio de composição, possivelmente dos mais seguros para a dura compreensáo tanto de quem trilhou os horrores da guerra como para quem se debruçou e se debruça nos dias de hoje e nele encontra, por meio do discurso literário, o poder da escrita poética, as armas da guerra, as armadilhas da história e da política, as vozes dos mortos e nossa memória de seres duplos como interrogantes e herdeiros.

A fim de orientar-nos de que o entendimento do século XX passa pelo conflito espanhol dos anos 1930, sobretudo na sua herança vigente até os dias de hoje, enquanto engrenagem dos despojos da Primeira Guerra que a antecede e, mais ainda, como o fundamento da Segunda Guerra Mundial, bastaria com ressaltar como isso implica nas noçôes de conceitos como fascismo, nazismo, sindicatos, partidos políticos, participação política, propaganda, cultura, vanguardas estéticas, direitos humanos 
etc., que, se não nascem todos no referido período, crescem e ganham corpo nele, recebendo suas devidas atualizações no tempo e no espaço. Essas questóes que permeiam o livro reiteram alguns aspectos vertebrais da Guerra Civil Espanhola, não apenas porque lançam mais luz para a leitura dos textos que a tomam como base ou referência, mas também porque instrumentalizam e enriquecem a abordagem da relação tão antiga e com muito a ser dito ainda entre Europa e América Latina, embora, aqui, a relação esteja centrada com a vanguarda poética latino-americana durante a vigência da II República espanhola. Desse modo, é preciso referir a clareza com que a autora discorre, amparada em farto material, sobre o ocorrido na Espanha na década de 1930, atestando como foram orientadas e definidas a consciência política, e sua consequente militância, de muitos autores; militância esta que se estende desde a filiação partidária até as intervençôes anarquistas e, ainda, na escrita, a incorporação de um patrimônio cultural popular e mesmo outros inclassificáveis procedimentos de transposição geográfica pela terra destruída e suas mortes irremediáveis na construção de uma poesia que percorre cartografias inusitadas por meio de paisagens multifacetadas, oriundas do sonho, da consciência erguida pela memória de pesadelo e realidade, mais a necessidade de seguir adiante pelo indescritível de estar vivo depois de tanta destruição.

A primeira grande pergunta que a autora se faz é como os escritores, poetas, cronistas, jornalistas e intelectuais, mas sobretudo os poetas latino-americanos se inscrevem numa vanguarda poética cuja escrita inevitavelmente produziu um imaginário social orientado pela guerra. 
Como as viagens e o intercâmbio de leituras, discussôes, correspondências e produção literaria contribuíram para criar os vínculos que tinham sua atençáo voltada sobre a guerra, em meio a um período também marcado pelas vanguardas artísticas no campo cultural e estético e, a partir daí, como se dá a relação dos escritores latino-americanos, notadamente os poetas, com os escritores espanhóis?

A Guerra Civil Espanhola encarna uma dimensão de horror tão ficcional que, a princípio, sua representação não encontraria dificuldade em convocar os recursos das experiências artísticas até então difundidas, as chamadas vanguardas, não fosse a guerra um fato consumado e sua destruição cada vez mais real e sem sentido. Dessa forma, a autora propóe o que considera sua questão central: uma vez que o conflito impactou de forma inaudita o imaginário entre vanguarda e política, o que considera uma nova instância da vanguarda, como podemos tratar las particularidades que asumió la vanguardia poética latinoamericana en la situación cultural de la guerra de España? O trajeto do estudo de Julia Miranda nos aponta uma sequência de releituras sobre leituras e de olhares sobre olhares de como os latino-americanos, direta ou indiretamente envolvidos no conflito, encararam, vivenciaram e incorporaram aos seus discursos, por meio de suas construçóes poéticas, ao acompanhar seus pares espanhóis que, sem alternativa, padeciam e enfrentavam o que decorria do apoio à causa republicana desde o seu início, como interventores culturais até o momento em que a atividade artística, pelo transcorrer da guerra, amalgamou-se à atividade política indissociavelmente. 
Julia Miranda. Frenética armonía. Vanguardias poéticas latinoamericanas en la Guerra Civil Española.

Por ser um estudo de ramificaçóes muito bem relacionadas na sua reconstituição cultural-histórica, são muitos escritores, jornalistas, fotógrafos, poetas e artistas mencionados, mas o corpus que protagoniza a investigação de Frenética armonía, resgata a produção poética de seis escritores que a autora julga centrais nas suas discussóes. São eles: Pablo Neruda (Chile), Raúl González Tuñon (Argentina), Vicente Huidobro (Chile), Cayetano Córdova Iturburu (Argentina), Juan L. Ortiz (Argentina) e César Vallejo (Peru). Com esses poetas, também são incorporadas as expressóes que norteiam suas atividades, tais como a participação no espaço público, o cosmopolitismo da guerra, a guerra dentro da guerra, isto é, as disputas ideológicas, a Guerra Civil como um marco cultural da Espanha moderna e, por fim, o conceito de poeta atuante, traço comum a esse significativo grupo de latino-americanos que, inicialmente pela palavra e, depois, adotando uma postura mais ativa, participam do conflito com suas atuaçóes diversas no campo do pensamento e da produção artística e literária e demais associações e congressos. Essas concepçóes, segundo a autora, convergem não apenas para resgatar a história das literaturas nacionais, mas sobretudo para dar conta dos desplazamientos, até então, inéditos. Tais concepçóes ainda explicam a postura desses poetas que assumiram e viveram a guerra como própria, o que os caracteriza como escritores de dupla nacionalidade, ou para ser mais fiel ao texto, imersos em doble territorialidad.

Transitando pela expressão de vanguarda, desde a sua ideia consensual que tem como base a arte experimental, a autora se posiciona com lucidez, 
não apenas por confrontar a noção limitada de vanguarda, mas também para mostrar a incompletude que a expressão "vanguardas históricas” encerra, como a reuniáo de todas as vanguardas que se enfeixam no seu intento principal de trançar a arte com a vida, tendo todas elas repousado no fracasso, inclusive as que se sucederam ao longo do século XX, sobretudo nos 1960 e 1970, como meras cópias de um patrimônio derrotado. Contrariando e alargando essa visão de Teoría de la vanguardia (Bürger, 1987), Julia Miranda aponta a impossibilidade, ou mesmo o olhar redutor, de se pensar a vanguarda apenas como uma procura formal de inovaçáo, apartando-a de complexidades sociais que ultrapassam os critérios teórico-críticos de produção durante o século XX. Essas complexidades não nos são dadas e recusam qualquer forma de projeto, pois se nutrem do imponderável que nasce como consequência de escolhas sociais que ultrapassam a vontade e a ação dos seus agentes. A guerra é uma dessas complexidades.

Apesar de generoso com a introdução das vozes que a autora concede a críticos de notória competência e às similares categorizaçóes destes sobre o conceito de vanguarda, o presente livro é claro e preciso no recorte que faz para a expressão em questão: tratar a vanguarda da poética latinoamericana na Guerra Civil Espanhola como o conjunto de fragmentos de um mundo que se esfacela sem a perspectiva do antigo-novo mundo que aparecerá sob seus escombros. A poesia de vanguarda na obra tratada é, por isso, e também pela utopia de representação conflituosa com a experiência vivida e o que se deseja numa proximidade-limite, uma construção poética e histórica: um testemunho do devir. Esse testemunho desagua 
Julia Miranda. Frenética armonía. Vanguardias poéticas latinoamericanas en la Guerra Civil Española.

em poemas e textos como ¡No pasarán!, Oda a España e Elegía a un joven muerto en el frente de Aragón, de Octavio Paz; España en el corazón, de Pablo Neruda; España, aparta de mi este cáliz, Himno a los soldados de la república e Invierno en la batalha de Teruel, de Cesar Vallejo; os poemas La muerte en Madrid, Los obuses, Los escombros e as crônicas Las puertas del fuego, de Raúl González Tuñon; Luna y rocio, A los poetas españoles e El ángel inclinado, de Juan L. Ortiz; Divertissment más o menos sombrio o un fusilamiento cada nueve minutos, de Córdova Iturburu; a crônica poética e homônima Vicente Huidobro habla desde Madrid, enfim, são suficientes para apontar uma redefinição da cultura de vanguarda, não apenas pelo teor de documento que tem o ideal de humanidade como seu norte, como também pela defesa da cultura na qual reside o mais significativo de expressão antropológica com a qual podemos olhar o fundamento do caráter social que nos inscreve no mundo de instituiçôes e suas instâncias produtoras de cultura que fomentam todo o aprendizado ao nos transmitir a herança de humanidade. Foi essa concepção conquistada ao longo do conflito, conforme demonstra sua autora, que orientou o pensamento e o posicionamento dessa vanguarda ampliada pelos laços de fraternidade que lutaram contra o fascismo e ampliaram sua capacidade crítica sobre suas consciências estrangeiras para encarar e testemunhar a luta sob uma bandeira que a todos representava.

Invocando Benjamin ao tratar do desenvolvimento sensorial que conduz à politização da arte em ambos os lados que travam a guerra, Julia Miranda não deixa de observar a morbidez do bando sublevado que provocara o 
conflito. Na posição oposta à defesa da República, da cultura e da liberdade, também os fascistas cantavam a guerra a seu modo, invocando o que de pior o passado histórico registra, nesse caso, as cruzadas. Anunciando a guerra de maneira a omitir a destruidora mão humana, atribuíam ao conflito uma vestimenta de anunciação divina, dando-lhe um aspecto de revelação para um novo mundo de salvaçáo de almas, um obscurantismo religioso que, devemos reconhecer, atendia bem às mais infames concepções e relações históricas possíveis, numa nebulosidade que politicamente era destituída de modernidade e esteticamente era destituída de humanidade. A tônica dominante do bando franquista estabelecia raízes com um passado arcaico de emblemas e símbolos de matriz nitidamente conservadora e irracional para justificar a opressão e os injustos estatutos de dominaçáo social: a vocação imperial da Espanha, o destino espanhol como pressuposto divino, o ser espanhol; enfim, recursos retóricos que só faziam aumentar a carga explosiva de um ânimo que, em meados da guerra, já náo objetivava nenhuma causa, nenhuma defesa, apenas a destruição da República pelo viés de uma obsessão ritualizada que, na prática, construía um valor diabólico sobre os termos comunista e rojos por meio de uma repetiçáo excessiva em seus discursos e palavras de ordem, desenhando em seus rostos o aspecto rígido e intratável de criaturas em esputação constante.

Por mais essa fresta, podemos ver o quanto se exigiu de criatividade, talento e trabalho dos republicanos, bem como dos vanguardistas, na sua missão de defender a naçáo espanhola do abismo fascista por meio da luz da razão, da ética política e da estética da cultura, ainda que, em 
Julia Miranda. Frenética armonía. Vanguardias poéticas latinoamericanas en la Guerra Civil Española.

ambos os lados, como os testemunhos apontam, promoveram-se abusos e injustiças, mesmo que em proporçóes muito desiguais. Dessa maneira, também se explica a inventividade do lado republicano e vanguardista na criação dos mais diversos meios tecnológicos de circulação de textos e ideias por meio da intensificação e de novos suportes que combinavam a palavra, a fotografia, os desenhos, cartazes, teatro e cançôes. A vanguarda latino-americana pode ser devedora no seu início em muitos aspectos à vanguarda europeia, mas as suas condições locais de política e cultura e a experiência no conflito espanhol avançaram e, pode-se dizer, superaram sua matriz emuladora ao escrever uma poesia nova de tradição literária e cultura popular, ao incorporar em sua própria poesia a escrita de uma história do presente que, ao mesmo tempo que alfabetizava os milicianos pró-república, selecionava da tradição as formas mais pertinentes para disseminar a cultura e a produção de vanguarda a partir das diferentes classes sociais, pois no horizonte desses poetas vanguardistas a junção da cultura literária popular e culta construía o novo olhar que deveria corresponder à urgência de uma criação sob o implacável ataque das bombas. É a partir desse ritmo de produção que Julia Miranda localiza nos textos, dentro do referido contexto histórico, o que representa muito bem o título do seu livro, na verdade os versos 63-66 da 4a estrofe do poema de César Vallejo, o já citado Himno a los soldados de la república: 


\section{Proletario que mueres de universo, jen qué frenética armonía acabará tu grandeza, tu miseria, tu vorágine impelente, tu violencia metódica, tu caos teórico y práctico, tu gana dantesca, españolísima, de amar, aunque sea a traición, a tu enemigo!}

(Vallejo, 1939, 281)

A frenética harmonia de que trata Vallejo e da qual tão bem se apropria a autora nos auxilia o olhar de uma criação de vanguarda, primeiro como sua etimologia militar que, associada aos ditames poéticos, nos dá o sentido da arte de avançar. Uma vanguarda como (r)evolução. E, nesse caso específico, vemos os novos imaginários sociais que cria para o século XX, para a arte do século XX, colhidos, em sua maioria, na intervenção social direta.

A autora já havia antecipado uma parte do seu trabalho num artigo que a revista Caracol publicou em seu número 6, o qual se detém na trajetória de construção das imagens poéticas latino-americanas e de como essas imagens se ampliam, deformam e se reconstroem a partir do contato e da experiência direta e indireta com a Guerra Civil Espanhola. Em termos gerais, a autora demonstra como os poetas latino-americanos retrabalharam sua poesia, por meio de uma reconfiguração semântica, entre outros expedientes, como uma ponte de comunicação que a guerra ameaçava destruir constantemente. No entanto, o mencionado artigo não deixava antever o volume e a extensa pesquisa de talento e fôlego que agora resenhamos, publicada pela editora Beatriz Viterbo no final de 2016, e que ainda reserva um capítulo raramente explorado, sobretudo entre nós, no Brasil, de diálogo entre a Guerra Civil Espanhola e a Literatura Brasileira. 
Julia Miranda. Frenética armonía. Vanguardias poéticas latinoamericanas en la Guerra Civil Española.

A incorporação de nomes consagrados da literatura brasileira ao trabalho de Julia Miranda não constitui propriamente uma surpresa nem uma novidade, dado que já é conhecida a produção dos nossos poetas que tomaram a guerra como mote e reflexão, principalmente a Segunda Guerra Mundial, como bem demonstra o alto rigor da pesquisa, apenas para citar um exemplo, de Murilo Marcondes de Moura sobre Cecília Meireles, Drummond e Murilo Mendes. No entanto, ao trazer nomes da poesia brasileira tão significativos para o seu trabalho sobre as vanguardas latino-americanas, o faz com justiça e entendimento crítico, sobretudo no que tange à tardia menção da Guerra Civil Espanhola nos textos desses autores, levando em consideração que o tempo transcorrido durante a Guerra Civil Espanhola corresponde, no Brasil, ao início do Estado Novo, 1937, e isso implica o reconhecimento do rígido controle que o DIP, Departamento de Imprensa e Propaganda do governo Vargas, exercia sobre a circulação de informaçóes, e a brutal vigilância sobre os dissidentes do regime político brasileiro de então, que durante muito tempo mantinha boas relaçôes diplomáticas com os regimes fascistas europeus e até mesmo certo alinhamento ideológico. Julia Miranda não deixa de enxergar aí, e com acerto, a dificuldade de se fazer difundir entre nós qualquer discurso que pudesse ameaçar a propaganda e a ideologia estado-novista que aqui se instalara, diga-se, com amplo apoio popular. No entanto, a autora não deixa de recordar as vozes que faziam chegar notícias da Espanha, como é o caso de La Gaceta Hispana, em que se publicavam as atrocidades que padeciam a resistência republicana espanhola, e um programa de rádio denominado 
Hora hispano-brasileira de España republicana. $\mathrm{O}$ canto à Espanha que levou à manifestação literária dos poetas brasileiros, mesmo anos depois do conflito, tais como Drummond, Mário de Andrade, Vinícius de Moraes e João Cabral, reafirma mais do que a vitória do cosmopolitismo e do internacionalismo extemporâneo do conflito espanhol, mostra a extensáo do poeta atuante por meio de uma consciencia histórica que só pode existir com memória e releitura. $\mathrm{O}$ distanciamento em testemunhar o ocorrido longe da urdidura do seu fato é concernente a toda história de lacunas, como o são as histórias brasileira e espanhola. A mordaça que se tramou nos dois lados do Atlântico hoje é puída e soa como uma cobrança fantasmagórica que indubitavelmente, passado o tempo que for, sempre há de triunfar sobre todas as perversóes ditatoriais político-sociais que elencam a narrativa esburacada das democracias latino-americanas e, como podemos ver, da história da nação espanhola também. É possível tratá-las de outro modo? É possível não percorrer a sequência trágica que a autora percorreu sem o trabalho de exumaçáo e confronto com o que fala depois de tanto tempo enterrado? Um verso de um grande exilado, ainda que em outro contexto de composição, revela-se profético e responde cabalmente a essas perguntas: "Imposible como aplacar ese fantasma que de mi evocasteis" (Cernuda, 2005, 548).

Em Espectros de Marx (Derrida, 1994), o filósofo francês assinala que "a herança não é jamais dada, é sempre uma tarefa. Permanece diante de nós, táo incontestavelmente que, antes mesmo de querê-la ou recusá-la, somos herdeiros, e herdeiros enlutados, como todos os herdeiros". No caso da 
Guerra Civil Espanhola, como a destruição em ambos os lados é ampla, o nosso olhar contemporâneo desenvolveu uma acertada consciência que recusa referir-se aos que lutaram pela República e aos que lutaram pelo fascismo como vencidos ou vencedores. Talvez a língua espanhola, mais precisamente a poesia em língua espanhola, seja o único triunfo em meio aos escombros. Sobras que de nós exigem o resgate de um duplo entendimento: o fabrico do testemunho e suas ressonâncias e ecos que nos orientam no campo movediço em que naufragam e tornam a emergir cultura, história e humanidade.

O que chamamos de "sequência trágica" no início desta resenha é enfrentada pela autora ao longo do seu estudo com excelentes pesquisa e bibliografia, desvelando e problematizando as relaçóes presididas pela prática vanguardista de linguagem e a condição humana na construção do social ao mesmo tempo que essa construção enfrentava a dissolução de suas bases e fundamentos durante a guerra. O desvelar dessa complexidade que nos apresenta Julia Miranda é, uma vez mais, a reiteração, jamais excessiva, do quanto excede nossa compreensão da literatura espanhola do século XX e contemporânea pelo olhar da Guerra Civil e, especificamente, no que reverbera e do que surge quando expandida na fraternidade da vanguarda latino-americana. 